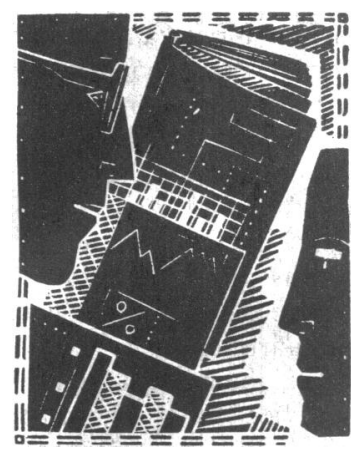

\title{
Adolescent self harm patients: audit of assessment in an accident and emergency department
}

\author{
Frank G O’Dwyer, Antoinette D’Alton, John B Pearce
}

\section{Abstract}

Objective-To examine the assessment of adolescent self harm patients attending an accident and emergency department.

Design-Retrospective assessment of case notes.

Setting-Accident and emergency department, Leicester Royal Infirmary.

Patients-210 adolescent patients (aged 9-19 years) attending the department during 1 January 1989-31 December 1989 after deliberate self poisoning; records were available for 200 .

Main outcome measures-Numbers of admissions, discharges from department without either a psychiatric consultation or some form of follow up, and discharges with either of these; scoring of adequacy of psychiatric and social assessment by accident and emergency doctor.

Results -89 patients were admitted (mean score $5 \cdot 1$, excluding 22 patients too drowsy or unforthcoming for proper assessment), 80 were discharged without specific psychiatric consultation or other follow up (mean score 5.4), and 31 were discharged with psychiatric consultation or other follow up (mean score 9.1). The percentage of patients in each group whose assessment by the accident and emergency doctor was considered to be adequate or better than adequate over $\mathbf{1 0}$ headings ranged from $0 \%-40 \%$ for admitted patients, $0 \%-50 \%$ for those discharged without psychiatric assessment, and $0 \%-61 \%$ in the remaining group. Overall, in almost half $(49 \%, 54 / 111)$ of all of those discharged documentation of the suicidal state was inadequate.

Conclusion-The assessment of many adolescent self harm patients in this clinic was unsatisfactory.

Implications-Doctors working in accident and emergency departments should be encouraged to liaise with child psychiatrists before discharging such patients.

Accident and Emergency Department, Leicester Royal Infirmary, Leicester LE1 5WW

Frank G O'Dwyer, FRCSI, registrar

\section{Child and Family}

Psychiatric Service, Leicester

Antoinette D'Alton, MRCPSYCH, senior registrar in child and adolescent psychiatry John B Pearce, FRCPSYCH, senior lecturer in child and adolescent psychiatry

Correspondence to: Mr O'Dwyer.

BMf 1991;303:629-30

\section{Introduction}

Deliberate self harm in young people has increased significantly in the 1960s and 1970s.' Since then this behaviour has gradually increased. ${ }^{2} \mathrm{~A}$ recent report indicated that the rate of suicide in young men aged 15 to 24 years increased dramatically in the 1980s. ${ }^{3}$ Controlled studies indicated high psychosocial morbidity in subjects who engage in deliberate self harm, ${ }^{45}$ about one in 10 adolescents making a further attempt leading to hospital referral during the year after an attempt. ${ }^{6}$ Recommendations regarding the assessment of children and adolescents advocate that ideally a short inpatient admission be used as an opportunity for prompt assessment by a member of the child psychiatry team for children aged between 12 and 16 years.

In Leicester a policy agreed between the accident and emergency department and the department of child and adolescent psychiatry requires that, as a minimum, consultation between the accident and emergency doctor and a child psychiatrist takes place before a young person who engages in deliberate self harm is discharged. Over the past decade there has been an increasing trend for adult patients to be discharged from accident and emergency departments without assessment by a psychiatrist. ${ }^{8}$ It seems that despite recommendations to the contrary a similar trend exists for young people. We therefore set out to audit the service provided for adolescents who engage in deliberate self poisoning.

\section{Patients and methods}

Patients aged between 9 and 19 years who attended the accident and emergency department of this hospital because of deliberate self poisoning between 1 January 1989 and 31 December 1989 were retrospectively identified from the department's computerised records. The child psychiatry service is available to all school attenders aged 18 years and under. Children aged under 9 years were excluded because most had attended owing to accidental ingestion. Patients who attended primarily because of alcohol or drug intoxication were also excluded.

The patients were divided into three groups: group A comprised patients admitted to hospital, group B those discharged without either a consultation with the on call child psychiatrist or some form of follow up, and group $\mathrm{C}$ those discharged after a psychiatric consultation or with some further follow up arrangement. The follow up arrangements varied from a recommendation to the patient to see his or her general practitioner to appointments arranged by the accident and emergency doctor with a child psychiatrist.

We examined the accident and emergency doctor's psychiatric and social assessments of the patient in each record and made a judgment on their adequacy. The information recorded was scored by using a modification of the scale devised by Kiernan et al to assess doctors' rating of the mental state examination. The headings used were modelled on those used by Black and Cread in assessing case notes of adult patients seen in an accident and emergency department after an overdose, ${ }^{10}$ but were modified to suit adolescent patients (box).

Ten categories were identified, and each received a score from 0 to 3 , where 0 was scored for no information, 1 for inadequate information, 2 for adequate information, and 3 for information of case conference standard. Five categories related to history, three to mental state, and two to social supports. The scoring system depended on the quality of the case notes made by the doctor as it required specific information in each category and by and large excluded information 


\section{Assessment headings ${ }^{\star}$ modified to suit adolescent patients}

1 Circumstances of the overdose: planning details, death wish, precipitant

2 Current circumstances including background problem

3 Previous history of self injury

4 Past psychiatric history or contact with psychiatric services

5 Family history

6 Depressed mood

7 Still suicidal

8 Evidence of psychosis

9 Interview with parents or relatives or friends. Attitudes of family towards further help

10 Patient's coping resources and supports

^From Black and Cread

that was implied rather than specifically stated. The maximum score possible was 30 . For those patients admitted to hospital a judgment was made as to the reason for this decision-that is, medical grounds, psychosocial grounds, or both. The records were independently scored by two of us (FGO'D and AD'A). Interrater agreement was assessed for each of the 10 headings separately, and a value for $x$ was determined, the $x$ values were all very similar, ranging from 0.89 to 0.94 and seem to indicate a high level of interrater agreement.

\section{Results}

Altogether 210 patients who satisfied the criteria were identified from the records. Records were not available for 10 patients, leaving 200 patients who formed the study group. Their mean age was 16.5 years and the sex ratio was 3:1 female to male. Eighty nine patients were admitted, of whom 12 were too drowsy for proper assessment and a further 10 were described as being reluctant to talk or unforthcoming; 31 were discharged after consultation or with follow up arrangements; and 80 were discharged without consultation or follow up arrangements. Of these 80 patients, one took discharge against medical advice and five were described as being unforthcoming about their overdose.

The mean total assessment score for patients who were admitted was $5 \cdot 1$ (median score 4 ), for those discharged with no follow up or consultation $5 \cdot 4$ (median score 5), and for those discharged with follow up $9 \cdot 1$ (median score 8 ). Patients were admitted on predominantly medical grounds with psychosocial factors contributing to the decision in 20 cases and being the predominant reason in five.

The table shows the numbers of patients in each group whose psychiatric and social assessments by

Number (percentage) of patients whose psychiatric and social assessments scored 2 or more (on information judged to be satisfactory)

\begin{tabular}{lccccccccccc}
\hline & \multicolumn{10}{c}{ Assessment headings } \\
& 1 & 2 & 3 & 4 & 5 & 6 & 7 & 8 & 9 & 10 \\
\hline Group A $(\mathrm{n}=67)$ & $24(36)$ & $23(34)$ & $27(40)$ & $7(10)$ & $4(6)$ & $12(18)$ & $25(37)$ & 0 & $9(13)$ & $2(3)$ \\
Group B $(\mathrm{n}=80)$ & $17(21)$ & $17(21)$ & $32(40)$ & $5(6)$ & $1(1)$ & $10(12)$ & $40(50)$ & 0 & $5(6)$ & $3(4)$ \\
Group C $(\mathrm{n}=31)$ & $13(42)$ & $19(61)$ & $13(42)$ & $8(25)$ & 0 & $11(35)$ & $17(55)$ & $2(6)$ & $10(32)$ & $10(32)$ \\
\hline
\end{tabular}

ॠSee box. the accident and emergency doctor were scored as adequate or more than adequate.

\section{Discussion}

Audit of the assessments carried out by the accident and emergency doctor disclosed several deficiencies in history taking, mental state examination, and assessment of social support. Overall assessment was judged as inadequate in many patients. Our impression that an appreciable number of this group of young people were being discharged from the department after assessment by only the accident and emergency doctor was confirmed, and a discharge rate of $40 \%$ in this age group seems very high. Of particular concern was the fact that for nearly half of all patients not admitted to hospital $(49 \%, 54 / 111)$ there was inadequate documentation as to whether they were still suicidal when they were discharged from the department. Also for 69 patients in this group (excluding the patient taking discharge against medical advice and the five uncommunicative patients) there was no reference to any discussion with the young person's parents, relatives, or friends. In many patients pre-existing problems identified by the doctor were not addressed.

When consultation or follow up had occurred the assessment seemed to have been more thorough. We wonder whether this suggests that improved assessment prompts consultation and follow up. This reflects a similar finding by Black and Cread..$^{10}$ We recognise that the assessment was judged on the documentation available, but as this was often the only record of a patient's attendance this ought to be an accurate record.

Many of the young people seemed to have been offered a less than satisfactory service. As a result doctors working in the accident and emergency department are now actively encouraged to discuss every adolescent self harm patient with the on call child psychiatrist before that patient's discharge, and further assessment, if appropriate, can then be arranged. As part of their assessment, doctors in the department are requested to fill in a checklist aimed at predicting the risk of repetition of the patient's self harm behaviour. This checklist was originally devised as a research tool but doctors in the department find it helpful when discussing individual patients with the child psychiatrist. We are now attempting to ascertain whether this policy is resulting in a change in the pattern of admission and follow up for these patients.

I Bancroft JH, Skrimshire AM, Reynolds F, Simkin S, Smith J. Self poisoning and self injury in the Oxford area: epidemiological aspects 1969-73. British Journal of Preventive and Social Medicine 1975;29:170-7.

2 Hawton $M$, Goldacre $M$. Hospital admissions for adverse effects of medicinal agents (mainly self-poisoning) in the Oxford region. Br $\mathcal{F}$ Psychiatry

3 Burton P, Lowy A, Briggs A. Increasing suicide rates among young men in England and Wales. BMF 1990;300:1695-6.

4 Taylor EA, Stansfield SA. Children who poison themselves. I. A clinical comparison with psychiatric controls; II. Prediction of attendance for treatment. Br f Psychiatry 1984;145:127-35.

5 Oto U. Suicidal acts by children and adolescents. Acta Psychiatr Scand 1972;suppl 233:7-123.

6 Hawton K. Suicide and attempted suicide among children and adolescents. Beverly Hills, California: Sage Publications, 1976:124.

7 Black M, Erulkar J, Kerfoot $M$, Meadow R, Baderman $H$. The management of parasuicide in young people under 16: report from the child and adolescent psychiatry section. Bulletin of the Royal College of Psychiatrists 1982;6:182-5. 8 Owens D. Self harm patients not admitted to hospital. $\mathcal{F} R$ Coll Physicians Lond 1990;24:281-3.

9 Kiernan W, McCreadie R, Flanagan W. Trainees' competence in psychiatric case writing. Br f Psychiatry 1976;129:167-72.

10 Black D, Cread F. Assessment of self-poisoning by psychiatrists and junior medical staff. F $R$ Soc Med 1988;81:97-9.

(Accepted 28 fune 1991) 